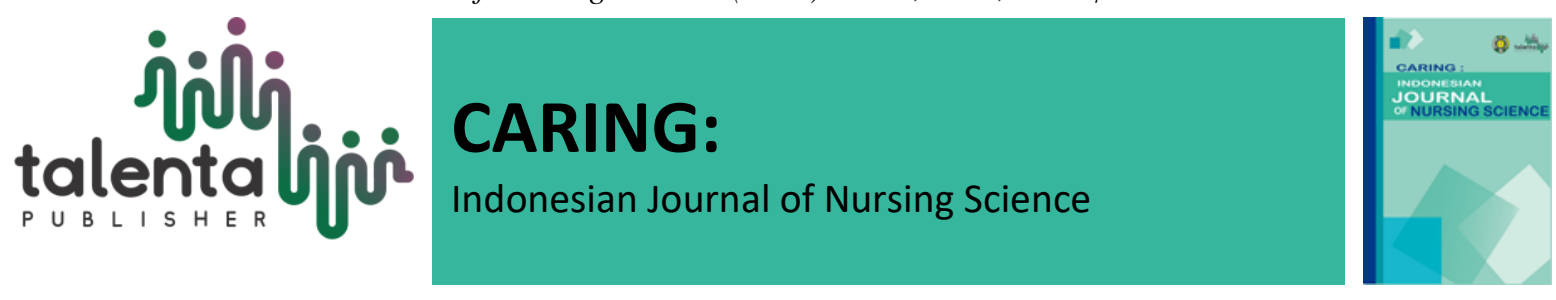

\title{
A Prospective Study On Pathology Distribution of Dizziness Patients in Neuro-Otology Department at National Hospital for Neurology \& Neurosurgery, Queen Square, London
}

\author{
Zainun $Z^{1}$, Davies R.A ${ }^{2}$, Marti $^{3}$ \\ Senior Medical Lecturer, Audiology Program, School of Health Sciences, Universiti Sains Malaysia \\ (USM), Malaysia
}

\begin{abstract}
Dizziness" is a general term [1] and covers a variety of 'abnormal sensations relating to perception of the body's relationship to space' [2]. According to the previous paper, Drachman and Hart [3] dizziness can be divided into four subtypes: vertigo, presyncope lightheadedness, disequilibrium, and other dizziness. Among all these subtypes, vertigo is one of the most commonly reported symptoms by the vestibular disordered patient nowadays [1]. Globally dizziness is one of 'the common, chronic and untreated symptoms' among the population in the age range of 18-65 years old. [4]. aims: To assess the pathology distribution among dizziness patients in NHNH. Method: All 97 patients were selected from an age range of 18-75 years, with a mean age of 47.92 (S.D=13.17). Method: All 97 patients were selected from an age range of 18-75 years, with a mean age of 47.92 (S.D=13.17). They were asked to fill in the VSS and MVSS questionnaires. Results: We were able to invite all 109 patients to participate our study within the 39 days (13 November - 21 December 2007) that's attended the Neuro-otology clinic, NHNN. Conclusion: In this study it has been found that women commonly presented with the dizziness symptoms compared to men.
\end{abstract}

Keyword: modified vertigo symptom scale, pathology, vertigo symptom scale, vestibular disordered

Received 14 June 2020 | Revised 12 July 2020 | Accepted 16 July 2020

\section{Introduction}

"Dizziness" is a general term [1] and covers a variety of "abnormal sensations relating to perception of the body's relationship to space' [2]. According to the previous paper, Drachman and Hart [3] dizziness can be divided into four subtypes: vertigo, presyncope lightheadedness, disequilibrium, and other dizziness (Table 1). Among all these subtypes, vertigo is one of the most commonly reported symptoms by the vestibular disordered patient nowadays, when defined as 'illusion of movement that commonly presents with a sense of rotation or sometimes a feeling of linear displacement or tilt' [1]. Studying to this symptom in detail, in terms of

*Corresponding author at:16150 Kubang Kerian, Kelantan, Malaysia.

Corresponding email: drzuraida@yahoo.com

Copyright (C) Published by Talenta Publisher, ISSN: 2580-6769 e-ISSN: 2580-829X

Journal Homepage: https://talenta.usu.ac.id/IJNS 
frequency, duration and aggravation factors will be useful in further diagnosis and the appropriate managements [1]. Globally dizziness is one of 'the common, chronic and untreated symptoms' among the population in the age range of 18-65 years old. [4]. The possibility and risk for a person to have these symptoms is quite high: about 93 per 1000 people affected each year [5]. Among the United Kingdom (UK) population, as a whole the prevalence of 'giddiness, dizziness, unsteadiness or light headedness' is $40 \%$ [6], and involves one in four of the Welsh community in the age range of 50-65 years. Otherwise, in London the only complaint of 'giddiness or difficulty keeping balance' is only $20 \%$ among $25-64$ year olds [7].

\section{Table 1. Approach to the Differentiation of Dizziness Subtypes [1]}

\begin{tabular}{|c|c|c|c|}
\hline Diziness Subtype & Type of Sensation & Temporal Characteristics & Other Specifications \\
\hline Vertigo & $\begin{array}{l}\text { A feeling that one or one's surroundings } \\
\text { are moving (typically, spinning) }\end{array}$ & $\begin{array}{l}\text { Episodic vertigo occurs in attacks } \\
\text { that last seconds to days } \\
\text { Continuous vertigo is present all or } \\
\text { most of the time for at least a } \\
\text { week }\end{array}$ & $\begin{array}{l}\text { Descriptions of episodic vertigo should include } \\
\text { the characteristics, duration, and date of the } \\
\text { first episode; length of episodes, and } \\
\text { exacerbating factors }\end{array}$ \\
\hline Presyncope & $\begin{array}{l}\text { A lightheaded, faint feeling, as though } \\
\text { one were about to pass out }\end{array}$ & $\begin{array}{l}\text { Typically occurs in episodes lasting } \\
\text { seconds to hours }\end{array}$ & $\begin{array}{l}\text { The following questions should be answered: 1) } \\
\text { Has syncope ever occurred during an episode? } \\
\text { 2) Do episodes occur only when the patient is } \\
\text { upright, or do they occur in other positions? } \\
\text { 3) Are episodes associated with palpitations, } \\
\text { medication, meals, bathing, dyspnea, or chest } \\
\text { discomfort? }\end{array}$ \\
\hline Disequilibrium & $\begin{array}{l}\text { A sense of unsteadiness that is 1) } \\
\text { primarly felt in the lower extremities, } \\
\text { 2) most prominent when standing or } \\
\text { walking, and 3) relieved by sitting or } \\
\text { lying down }\end{array}$ & $\begin{array}{l}\text { Usually present, although it may } \\
\text { fluctuate in intensity }\end{array}$ & $\begin{array}{l}\text { Identify whether symptom occurs in isolation or } \\
\text { accompanies another dizziness subtype; } \\
\text { describe exacerbating factors }\end{array}$ \\
\hline $\begin{array}{l}\text { Other dizziness: } \\
\text { anxiety-related, } \\
\text { ocular, tiling } \\
\text { environment, other }\end{array}$ & $\begin{array}{l}\text { A feeling not covered by the above } \\
\text { definitions. May include swimming or } \\
\text { floating sensations, vague } \\
\text { lightheadedness, or feelings of } \\
\text { dissociation. May be difficult for the } \\
\text { patient to describe }\end{array}$ & $\begin{array}{l}\text { Usually present all or most of the } \\
\text { time for days or weeks, } \\
\text { sometimes years }\end{array}$ & $\begin{array}{l}\text { The following questions should be answered: 1) } \\
\text { Is dizziness associated with anxiety or hyper- } \\
\text { ventilation? 2) Was change in vision } \\
\text { connected with dizziness onset? 3) is diziness } \\
\text { a sensation that the environment is tilting } \\
\text { sideways (suggests an otolith problem)? }\end{array}$ \\
\hline
\end{tabular}

Drachman DA, Hart CW. An approach to the dizzy patient. Neurology. 1972;22:323-34.

The problem or difficulties are more marked if working people are studied, where one figure showed 'one in five of working people' experienced dizziness symptom [4]. From these figures almost $40 \%$ of dizzy people face a problem carrying out their job [4]. In conclusion, the percentage of cases and age distributions showed that dizziness is one of age related illness, as we can see from the distribution of the patients which is more deviated toward adults and the elderly [4], and more toward women than men [2-5,9]. Dizziness is one of the general symptoms that are commonly reported from patients to the clinician at all levels, and most of these patients are seen at 'Ear, Nose and Throat (ENT) and also Neurology departments' for further management [1]. The percentage prevalence for all the causes for dizziness varies depending on the age, site of study (primary, secondary and tertiary centres) and definition and classification used for dizziness itself. They potentially have a variety of possible etiological factors (Table 2) [8], and the most common cause of dizziness is peripheral vestibular disorder $[13,19 \& 20]$. Obviously in primary care, acute labyrinthitis (or vestibular neuritis) is the most common diagnosis made for the Peripheral Vestibular disorder PVD and most of their symptoms are manageable [8]. Otherwise in tertiary referral centre 'recurrent peripheral vestibular disorder i.e. recurrent benign paroxysmal positional vertigo (BPPV), recurrent 
vestibulopathy [9], and Meniere's disease [10] are predominating'. [1, 7, 14, 15]. As mentioned above, vertigo is 'a feeling that one or one's surroundings are moving (typically, spinning)' [3] and is strongly correlated with vestibular disorder [1].

\section{Table 2. Cause of Dizziness}

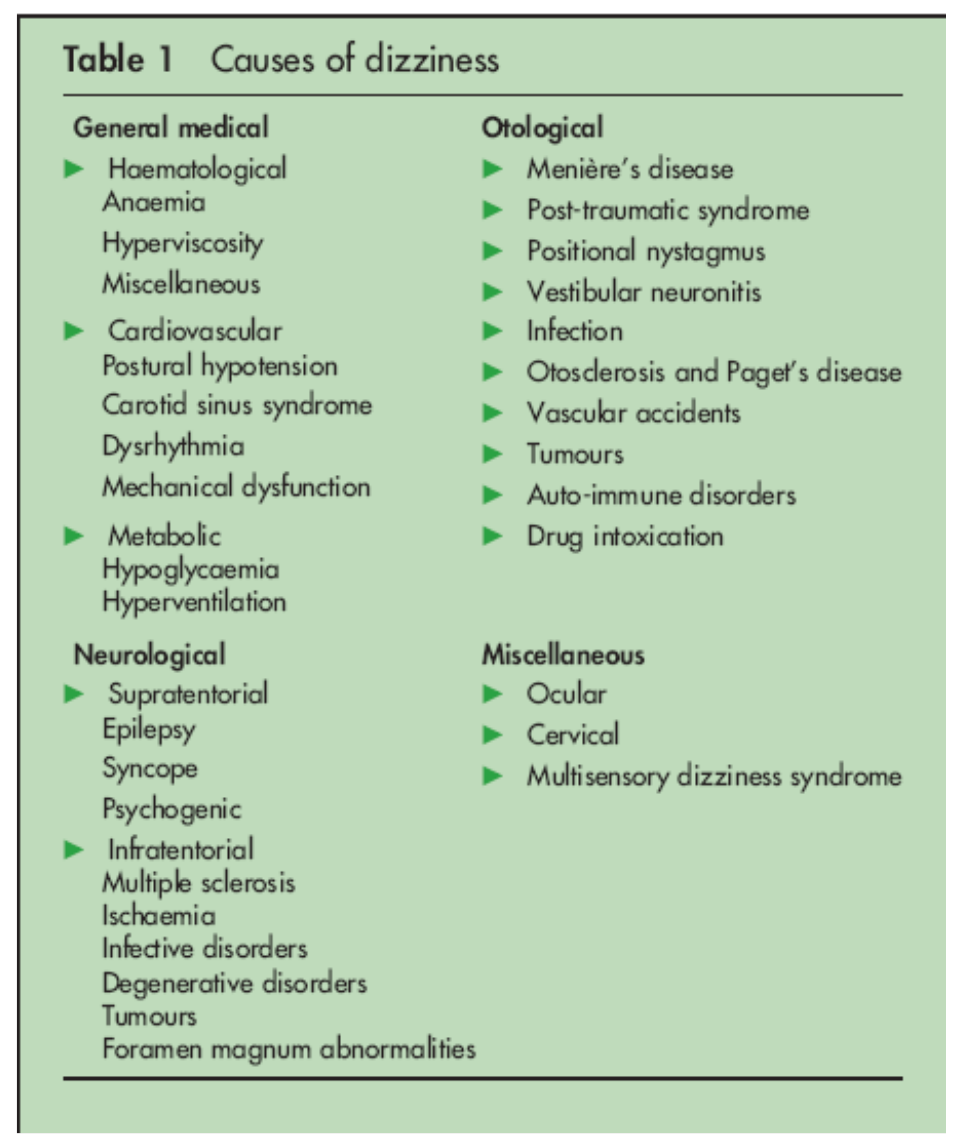

Source: Kroenke K, Lucas CA, Rosenberg ML, Scherokman B, Herbers JE Jr, Wehrle PA, Boggi JO Causes of persistent dizziness. A prospective study of 100 patients in ambulatory care Ann Intern Med. 1992 Dec 1; 117(11):898-904

\section{Research Methods}

All 110 dizziness patients randomly collected that have attended the Neuro-otology department at National Hospital for Neurology \& Neurosurgery, Queen Square, London were invited randomly to participate for our study. End of the data collection, only 97 cases from both groups completed both questionnaires and some of them were excluded once they unable to fulfill the inclusion and exclusion criteria. Patients an age range is 18-75 years, with a mean age of 47.92 ( $\mathrm{S} . \mathrm{D}=13.17$ ). The means age for group 1 is 49 ( $\mathrm{S} . \mathrm{D}=13.84$ ) and group $2=46.92$ ( $\mathrm{S} . \mathrm{D}=12.58$ ). Male to female ration are 2:3 for group 1 and 1:4 for group 2 (Table 1).

Selected patient from Neuro-otology clinic have been informed and invited to participate in the study. After consent, questionnaires (VSS and MVSS), patients' information sheet and a consent form was given to all patients that fulfill the inclusion and exclusion criteria. Inclusion 
criteria are the newly referred patient with dizziness, the dizzy patients seen at follow-up who have completed a minimum of 3 months' balance exercises and age 18-75 years old. Exclusion criteria are patients with central causes of dizziness, progressive vestibular disorders i.e. Meniere's disease and age $<18$ and $>75$ years old. The study was approved by the Ethic Committee National Hospital neurology and Neurosurgery (NHNN) with reference number 06/Q0512/54. All the data collected analyzed using SPSS software version 14.0. In this study we are going to include most dizzy patients with vestibular disorders patients such as poorly compensated peripheral vestibular disorder (PCPVD), BPPV and others that have been excluded all the central lesion.

\section{Result and Discussion}

We were able to invite all 109 patients to participate our study within the 39 days (13 November - 21 December 2007) that's attended the Neuro-otology clinic, NHNN. Among these patients, only 97 cases returned and complete the questionnaires.

There were only 3 patients that refused to participate, 3 patients did not fully complete the questionnaire, 2 patients returned the questionnaire late and exceed the due date for them to return back and 6 patients have not returned the questionnaires even after a few remaining by mail and phone. All the involved patients were selected from an age range of 18-75 years, with a mean age of 47.92 ( $\mathrm{S} . \mathrm{D}=13.17$ ). The means age for group 1 is 49 ( $\mathrm{S} . \mathrm{D}=13.84$ ) and group 2 $=46.92(\mathrm{~S} \cdot \mathrm{D}=12.58)$. According to the gender distribution for both group of samples we can see the ratio for male to female in group 1 is $2: 3$ and group 2 is 1:4 (Table 5). Almost $66 \%$ (28 cases) of all newly referred cases (group1) are women and $75 \%$ (41 cases) of follow up cases are women (Table 3).

Table 3. Patient characteristic that involved in this validation study

\begin{tabular}{lcc}
\hline & Group 1 & Group 2 \\
\hline Subject $(\mathrm{n})$ & 47 & 51 \\
Age & $49(\mathrm{~S} . \mathrm{D}=13.84)$ & $\mathrm{B}=46.92(\mathrm{~S} . \mathrm{D}=12.58)$. \\
Sex M/F & $19 / 28$ & $10 / 41$ \\
\hline
\end{tabular}

Data showed as mean \pm SD or number. M: male; F: female

Pathology distribution of Group 1 and 2: In general, most of the patients in these two groups have vestibular problems where almost $38 \%$ of patients have Peripheral Vestibular Disorder and $12 \%$ have Vestibular Migraine (Figure 1). Additionally, there is a high number of patients, approximately $18 \%$ that remain undiagnosed (unknown). Comparing the distribution of the problem between both groups, it can be seen that they are fairly homogenous, such as BPPV, Bilateral Vestibular Failure, Migraine Related Dizziness, Autonomic Vertigo and Dizziness Anxiety Related in both group is quit homogenous and no mark different between group 1 and 2 (Table 4). In term of Peripheral Vestibular Disorder (PVD) and all that three type of migraine is 
more common in group 2 than group 1 . In group 1 an almost 14 patients are in unknown categories compare to group 2 only 4 patients, where it means there is no firm diagnosis now.

\section{Figure 1. Distribution diagnosis in both groups}

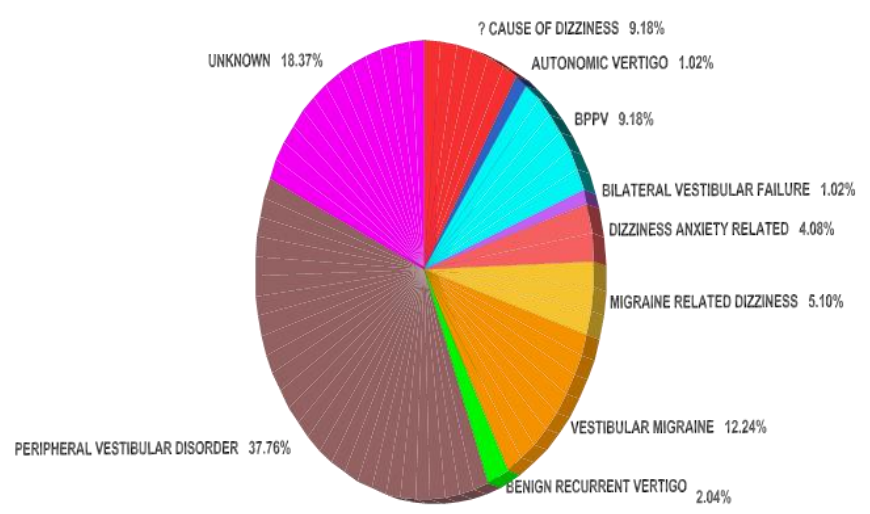

Table 4. Diagnosis distribution in each group

\begin{tabular}{|c|c|c|c|}
\hline \multirow[b]{2}{*}{ Diagnosis } & \multicolumn{2}{|c|}{ Group } & \multirow[t]{2}{*}{ Total } \\
\hline & 1 & 2 & \\
\hline CAUSE OF DIZZINESS & 6 & 3 & 9 \\
\hline AUTONOMIC VERTIGO & 1 & 0 & 1 \\
\hline BPPV & 5 & 4 & 9 \\
\hline $\begin{array}{l}\text { BILATERAL } \\
\text { FAILURE }\end{array}$ & 1 & 0 & 1 \\
\hline $\begin{array}{l}\text { DIZZINESS } \\
\text { RELATED }\end{array}$ & 2 & 2 & 4 \\
\hline MIGRAINE(1) & 1 & 4 & 5 \\
\hline MIGRAINE(2) & 4 & 8 & 12 \\
\hline MIGRAINE(3) & 0 & 2 & 2 \\
\hline PVD & 13 & 24 & 37 \\
\hline UNKNOWN & 14 & 4 & 18 \\
\hline Total & 47 & 51 & 98 \\
\hline
\end{tabular}

* Migraine 1. Benign Recurrence Vertigo

2. Migraine related Dizziness

3. Vestibular Migraine

Female number is more compared to male in both newly referred and follow-up patients. Almost $66 \%$ (28 cases) of all newly referred cases (group1) are women and also $75 \%$ (41 cases) of follow up cases are women. In parallel with the other studies [18, 24], it has been found that women were especially involved and presented with the dizziness symptoms compared to men. Additionally, the reason why men are less involved in these studies than women is possibly owing to their nature, where men are less aware and follow all the appointment given or maybe because of their time limitation with a heavy workload causing them to delay seeking treatment for their problem. We can see in some prevalence studies of dizziness where BPPV is one of the common causes of vertigo. There several etiological factors 
for BPPV and the prevalence for idiopathic BPPV itself is 11-64 over 100000 in one year and two time more common in female than male $[22,23]$.

Generally, our real intention and main target is all the patients that attended Neuro-otology clinic that have varies symptom of dizziness such as vertigo, light-headache, imbalanced and others dizziness subgroup symptom. If we see and compare the distribution of the problem between both groups, they are quite homogenous and not much different such as BPPV, Bilateral Vestibular Failure, Migraine Related Dizziness, Autonomic Vertigo and Dizziness Anxiety Related. Compare to the both group, peripheral vestibular disorder (PVD) and all that three type of migraine is more common in group 2 than group 1 . In group 1 almost 14 patients are in unknown categories compare to group 2 only 4 patients, where it means there is no firm diagnosis. According to the distribution of diagnosis we can realize that almost 14 patients are still undiagnosed in the group 1 . This is because for group 1 this is first time appointment and they still need to undergo others detail investigation where some of the test need to book for appointment, furthermore our study site is one of the one-stop clinic where almost all patients still need further investigation such as CT-scan, MRI Magnetic Resonance Imagine) and others test which is sometime have had long waiting list that will lead to the delay of definite diagnosis for their problem.

The others reason for our newly referred patients in group 1 most of them still don't have confirmed diagnosis and also some of the patients finished their entire test late in the afternoon and that because we miss their diagnosis. In the group 2 the most common problem patients have is Peripheral Vestibular Disorder (PVD) i.e. poorly compensated PVD, Positional recurrence PVD, Positional related PVD, Possible PVD, Right or left PVD and labyrhintitis in about 24 patients. In term of severity we cannot assumed that the group 1 is more severe compared to the group 2 even all of them are new case and never seek for medical or rehabilitation treatment. Such as in the cases of poorly compensated PVD we can see the pattern of symptoms are quit fluctuate and most patients will be suffered from all the chronic and secondary symptoms which is will make the patient's condition more worsen and distorted almost all the time. Even in the total score both version VSS most of them will be in high score group where indicate that their symptoms are severe. Future study with bigger sample size needed in order have more accurate and detail data.

\section{Acknowledgement}

Author would like to thank the respondents for all valuable data provided in this research.

\section{Conflict of Interest}

There is no conflict of interest in this research result. 


\section{REFERENCES}

[1] Robert W Baloh MD. Vertigo. The Lancet Volume 352, Issue 9143, 5 December 1998, Pages 1841-1846

[2] Kroenke K, Price RK. Symptoms in the community. Prevalence, classification, and psychiatric comorbidity. Arch Intern Med. 1993;153:2474-80.

[3] Drachman DA, Hart CW. An approach to the dizzy patient. Neurology. 1972;22:323-34.

[4] Yardley L, Owen N, Nazareth I, Luxon L. Prevalence and presentation of dizziness in a general practice community sample of working age people Br J Gen Pract. 1998 Apr; 48(429):1131-5.

[5] Tinetti ME, Williams CS, Gill TM. Dizziness among older adults: a possible geriatric syndrome. Ann Intern Med. 2000;132:337-44.

[6] Coles RRA, Sinclair A. The vestibular system. In: Edwards SC, McCallum RI, Taylor PJ. (eds). Fitness for work. 1st edn. Oxford: Oxford University Press, 1988.

[7] Patrick DL, Peach H. Disablement in the community. Oxford: Oxford University Press, 1989.

[8] Eugene CK Kwong and Nicholas JG Pimlott Assessment of dizziness among older patients at a family practice clinic: a chart audit study BMC Family Practice 2005, $6: 2$

[9] Rutka JA, Barber HO. Recurrent vestibulopathy: third review. J Otolaryngol.1986;15:105-7.

[10] Kroenke K, Hoffman RM, Einstadter D. How common are various causes of dizziness? A critical review. South Med J. 2000;93:160-7. 